\title{
East Asian Astronomical Records
}

\author{
F. Richard Stephenson \\ Department of Physics, University of Durham, DH1 3LE, United \\ Kingdom
}

\begin{abstract}
Chinese, Japanese and Korean celestial observations have made major contributions to Applied Historical Astronomy, especially in the study of supernovae, comets, Earth's rotation (using eclipses) and solar variability (via sunspots and aurorae). Few original texts now survive; almost all extant records exist only in printed versions, often with the loss of much detail. The earliest Chinese astronomical observations extend back to before $1000 \mathrm{BC}$. However, fairly systematic records are only available since $200 \mathrm{BC}$ - and even these have suffered losses through wars, etc. By around AD 800, many independent observations are available from Japan and Korea and these provide a valuable supplement to the Chinese data. Throughout East Asia dates were expressed in terms of a luni-solar calendar and conversion to the Julian or Gregorian calendar can be readily effected.
\end{abstract}

\section{Introduction}

By East Asia will be implied China along with its cultural satellites Korea and Japan. Vast numbers of observations of celestial events of all kinds are preserved from all three countries, forming a series of archives without equal anywhere else in the world.

Extant astronomical records from China commence around $1300 \mathrm{BC}$ (during the Shang Dynasty), but the earliest reliable observations do not begin until shortly before $700 \mathrm{BC}$. However, only after about $200 \mathrm{BC}$ do systematic series of Chinese observations commence, although these are very extensive. Although Korean records of celestial phenomena ostensibly start in the 1st century BC, before about AD 1000, they are relatively rare and are mainly copied from Chinese history. Later Korean astronomical records are original and are remarkably detailed. The earliest Japanese reports of celestial events date from the 7 th century AD. Especially after about AD 800, these are fairly detailed, but tend to be less systematic than those from China and Korea.

In general, East Asian manuscripts containing astronomical records are rare. Because of the early discovery of printing (China; 8th century AD), most records are in the form of printed texts, some of which have been copied and recopied many times. 


\section{Calendar}

The basic rules of the Chinese calendar have remained virtually unchanged for more than 2000 years. The traditional calendar is luni-solar; most years contain twelve lunar months, each of either 29 or 30 days. Every two or three years, a 13 th month is inserted to keep the calendar in step with the seasons. Already in the Shang Dynasty, a 60-day cycle was introduced and this cycle has continued without interruption for more than 3000 years. Years were not counted from a fixed origin. They were numbered either from the start of an emperor's reign or a reign period (a somewhat arbitrary division of a reign). Date conversion - to either the Julian or Gregorian calendars - is fairly straightforward using standard tables, or by computer programs based on these tables. The Chinese calendar spread to Korea (for so long a vassal state of China) and also to Japan. The mode of operation of the calendar in all three countries was almost identical, apart from the counting of years; Korean and Japanese sovereigns adopted their own year count.

\section{Chinese observations}

The Shang Dynasty records are essentially divination texts (inscribed on bone fragments) and contain few observations. However, several references to eclipses - and possibly other celestial phenomena - have been identified. The interpretation of many of the primitive characters inscribed on these "oracle bones" is still uncertain. Although a number of dates of celestial events are recorded, they are incomplete; the year is never given and the month only rarely so. Hence despite the regular usage of the 60-day cycle, it is not possible to derive unambiguous dates with any confidence.

The Shang Dynasty ended around 1050 BC. Over the next three centuries (the early Zhou Dynasty), virtually no celestial observations are preserved. Not until more than 300 years later do we encounter reasonably regular astronomical records. These are found in the Chunqiu ("Spring and Autumn [Annals]"), a chronicle of $\mathrm{Lu}$ - one of the early feudal states of China - and cover the period from 722 to $480 \mathrm{BC}$. The Chunqiu presumably survived because of its association with Confucius; according to tradition, he compiled the chronicle. The Chunqiu is remarkable for its set of 36 solar eclipse observations - the earliest such series from any part of the world.

During the subsequent Zhanguo or Warring States Period - from about 480 to $221 \mathrm{BC}$ - celestial observations from China are rare. A few records of comets and solar eclipses (but nothing else) from this period are found in the Shiji ("Historical record"), compiled by Sima Qian around 100 BC. In most cases only the year of occurrence is given.

Following the unification of China in $221 \mathrm{BC}$ by Chin Shihuang, imperial astronomers were appointed to maintain a regular watch of the sky for celestial omens. Commencing with the long-lived Han Dynasty (206 BC-AD 220), and extending down to the Qing Dynasty (AD 1644-1911), Chinese astronomical records are very extensive. A fundamental source of observations is the official dynastic histories, which were usually compiled by a team of scholars soon after the demise of a dynasty. Many of these works contain detailed astronomical 
treatises devoted to the recording and interpretation of celestial portents. These treatises note numerous events such as solar eclipses, conjunctions of the Moon with planets, lunar and planetary movements among the constellations, "guest stars" (usually novae with occasional supernovae), comets, meteors, the aurora borealis and sunspots. Virtually every kind of celestial phenomenon which might attract the attention of the unaided eye is reported in these works. Although it is clear that the original records are often significantly abbreviated, in almost every case the precise date of a celestial event is cited. The imperial annals of the dynastic histories also contain many parallel records of the same phenomena, but usually in less detail than in the astronomical treatises. Eclipses are also frequently reported in special calendar treatises, sometimes with estimates of the time of day or night.

Ho Peng Yoke (1966) translated into English the astronomical treatise of a sample dynastic history - from the Jinshu ("History of the Jin Dynasty", covering the period from AD 220-420). However, so far this highly useful work remains unparalleled.

Valuable astronomical records are to be found in other Chinese historical sources. These include: the Wenxian Toungkao (an historical encyclopedia compiled by Ma Duanlin around AD 1300), together with later supplements; the Ming Shilu ("Annals of the Ming Dynasty": covering the period from AD 1367 to 1644); and large numbers of Fangzhi or "Local Histories". The local histories are particularly frequent after about $\mathrm{AD} 1500$, and prove to be a major source of celestial observations, many of which are lacking in the official histories.

Ho Peng Yoke \& Chiu Ling Yeong (1977) compiled a catalogue of all the celestial observations in the Ming Shilu, retaining the records in their original language. More recently, a team of Chinese scholars under the auspices of Beijing Observatory (1988) made a thorough compilation of astronomical records in a wide variety of Chinese sources: from earliest times until the end of the Qing Dynasty (AD 1911). All dates in this work have been converted to the Julian or Gregorian calendars.

\section{Korean observations}

There are four main sources of Korean astronomical records; each is written in Classical Chinese. The earliest work, the Samguk Sagi ("History of the Three Kingdoms"), covers the period from the first century BC to AD 918. It is a chronicle of the three ancient kingdoms into which Korea was divided: Koguryo, Paekche and Silla. Compiled in AD 1145 by Kim Pu-sik, it is partly based on original records which are no longer extant. However, Kim also supplemented his material from Chinese history. Reports of celestial phenomena are sparse, and are mainly copied from Chinese history. The history of the subsequent Koryo Dynasty (AD 918-1392) is modelled on the Shiji of ancient China. Known as the Koryo-sa, this work was completed in AD 1451 under the direction of Chong Inji. The Koryo-sa has an extensive astronomical treatise in three chapters, which in essence is indistinguishable from that of a typical Chinese dynastic history. The compilers used annals of the Koryo Dynasty which no longer exist.

For the final Korean dynasty, the Yi (AD 1392-1910), detailed annals are available: the Yijo Sillok ("Annals of the Yi Dynasty"); this is a substantial 
work, in many volumes. Events - both astronomical and mundane - are listed in purely chronological order. Photographic reprints of the Yijo Sillok are available in major libraries worldwide. Quite recently the Yijo Sillok has been made available on CD-ROM. From AD 1623 to 1894, an even more detailed chronicle is extant. Known as the Sunjongwon Ilgi ("Daily records of the office of the Royal secretaries"), this originally extended back to AD 1392. However, in $\mathrm{AD} 1592$ virtually all extant records were destroyed by Japanese invaders, and still more were lost in subsequent years. Photographic reprints are available in a few major libraries internationally.

\section{Japanese observations}

The earliest surviving Japanese astronomical records are from the 7th century AD. These are contained in the Nihon Shoki ("Chronicles of Japan"), a work which covers the period from ancient (legendary) times to the 7th century AD. The Nihon Shoki was compiled in AD 720. Another useful source is the Dainihonshi ("History of Great Japan"). This has a compact but useful astronomical treatise containing celestial records in a variety of categories. It extends down to about AD 1400. Other Japanese sources containing observations are much more scattered than their Chinese or Korean counterparts: for example, privately compiled histories and diaries of courtiers. Most early Japanese works are in Classical Chinese, but Kana syllabic symbols are frequently used in texts after about AD 1000.

Valuable compilations of Japanese celestial observations in a wide variety of sources have been published by Kanda (1934) and Ohsaki (1994). The compilation by Kanda covers the period from AD 600 to 1600, while Ohsaki extends this range from AD 1601 to 1867 . Dates are conveniently converted to the Julian or Gregorian calendars.

\section{Star maps}

In addition to written records describing celestial events, numerous star maps are preserved from China, Korea and Japan, especially after about AD 1000. These charts are of considerable value in studying observations of comets and guest stars since the reports of these phenomena frequently describe celestial positions in terms of constellations. Korean and Japanese star charts follow Chinese astrography with only minor variations. By comparing the representations of star groups on these maps with modern star charts and photographs of sections of the sky, it is usually possible to identify the constituent stars in terms of their Western equivalents.

\section{References}

Beijing Observatory 1988, Zhongguo gudai tianxiang jilu zongji ("A union table of ancient Chinese records of celestial phenomena") (Kiangxu: Kexue Jishi Chubanshe)

Ho Peng Yoke 1966, The astronomical chapters of the Chin Shu (Paris: Mouton) 
Ho Peng Yoke \& Chiu Ling Yeong 1977, Ming Shilu zhong zhi tianwen ziliao ("Astronomical records in the veritable history Ming Shilu") (Hong Kong).

Kanda Shigeru 1934, Nihon temmon shiryo ("Japanese astronomical observations") (Tokyo)

Ohsaki Shoji 1994, Kinsai Nihon Temmon Shiryo ("Pre-modern Japanese astronomical observations") (Tokyo: Hara Shobo) 